\title{
Reproductive performance in high producing dairy cows: practical implications
}

\author{
A. de Kruif', J. Leroy², G. Opsomer ${ }^{1}$ \\ 'Department of Reproduction, Obstetrics and Herd Health; Faculty of Veterinary Medicine, Merelbeke, Belgium, ${ }^{2}$ Laboratory \\ for Veterinary Physiology, Department of Veterinary Sciences, University of Antwerp, Belgium
}

Key words:

Dairy cow, milk production, reproductive disorders, management

Schlüsselwörter:

Milchkuh, Milchproduktion, Reproduktionsstörungen, Management

\begin{abstract}
Summary:
Several studies have clearly demonstrated that the fertility of high yielding dairy cows has declined over the past 25 years. The resumption of ovarian activity post partum has been retarded and conception rates have dropped significantly from 55 to $40 \%$. Accordingly, the calving interval has increased from about 385 days to 417 days. The percentage of cows culled because of infertility has risen from 5 to $8 \%$ per year. The "subfertility syndrome" is a multifactorial problem. As the negative energy balance and general health status after calving are known to be paramount factors hampering fertility, it is apparent that avoiding both is among the most important preventive measures to be taken. Improvement of the energy status by achieving a high dry matter intake and the provision of optimal and well balanced nutrition during the transition period as well as during early lactation are key goals in this effort. To achieve these goals, we should not only calculate the rations on paper, but should also check in the stable to determine whether the calculated amount is really being consumed by the cows. Furthermore, veterinarians should use their "clinical eyes" as well as other diagnostic tools to assess the general health status of the cows and to assess at which aspect of the process things are going wrong and need to be adjusted. Besides the control of the negative energy balance and health status, other management factors that need to be maximized include heat detection, cow comfort, insemination technique, time of insemination during estrus and sperm quality. Only if management is on a very high level high milk production and good fertility can be a feasible combination.
\end{abstract}

\begin{abstract}
Zusammenfassung:
Mehrere Studien haben eindeutig gezeigt, dass die Fruchtbarkeit von Hochleistungsmilchkühen in den vergangenen 25 Jahren zurückgegangen ist. Die Wiederaufnahme der Ovarfunktion post partum findet verzögert statt und die Konzeptionsraten sind signifikant von $55 \%$ auf $40 \%$ abgefallen. Entsprechend hat sich das durchschnittliche Kalbungsintervall von etwa 385 Tagen auf 417 Tage erhöht. Der Prozentsatz an Kühen, die aufgrund von Infertilität geschlachtet werden, ist von $5 \%$ auf $8 \%$ pro Jahr gestiegen. Das "Subfertilitätssyndrom" stellt ein multifaktorielles Problem dar. Bekanntermaßen sind eine negative Energiebilanz und ein schlechter Allgemeinzustand nach dem Kalben bedeutende Faktoren, die die Fruchtbarkeit negativ beeinflussen können. Konsequenterweise gilt es als wichtigste präventive Maßnahme, diese beiden Zustände zu verhindern. Schlüsselelemente dabei sind die Verbesserung des Energiestatus durch eine hohe Trockensubstanzaufnahme sowie die Sicherstellung einer optimalen und ausgewogenen Ernährung während der Übergangs- und frühen Laktationsperiode. Um dies zu erreichen, reichen schriftliche Berechnungen allein nicht aus, sondern es muss die tatsächliche Futteraufnahme der Kühe im Stall kontrolliert werden. Ferner sollte der Tierarzt seinen „klinischen Blick“ und diagnostische Verfahren einsetzen, um den Allgemeinzustand der Kühe zu beurteilen und zu erkennen, wo Probleme auftreten, damit diese behoben werden können. Neben der Kontrolle der negativen Energiebalanz und des Gesundheitsstatus gilt es, weitere Managementfaktoren wie Brunstbeobachtung, Wohlbefinden der Kühe, Besamungstechnik, Besamungszeitpunkt im Östrus und Spermaqualität zu optimieren. Nur bei optimalem Management ist eine Kombination von hoher Milchleistung und guter Fruchtbarkeit möglich.
\end{abstract}

Reproduktionsleistung hochleistender Milchkühe: Auswirkungen für die Praxis

Tierärztl Prax 2008; 36 (Suppl 1): S29-S33

\section{Introduction}

At present dairy cows are able to produce vast amounts of milk mainly due to significant genetic improvements, combined with enhanced nutritional management. A prerequisite for good lactation performance during the cow's life span is producing a calf at regular intervals. Therefore reproductive efficiency is a world- wide concern in the dairy industry as it influences average daily milk production, average days in milk, number of calves born per year and the generation interval (3). Many studies have reported a worrisome decrease in the reproductive performance of dairy cows and this problem seems to affect all countries housing high yielding dairy herds. 
Reproductive performance in high producing dairy cows: practical implications

A. de Kruif, J. Leroy, G. Opsomer

For example, in Belgium the average calving interval increased from 390 to 417 days during the last 12 years. The number of AI per conception rose from 1.43 to 1.80 in the same period and the pregnancy rate at first AI dropped from 56 to $43 \%$.

\section{Economic consequences of subfertility}

There is no doubt that fertility failure has a major negative economic impact. The extra costs arising from subfertility include lost income from milk and calf sales, feed and quota costs, extra veterinary and semen expenditures, and the costs associated with culling and extra replacement of subfertile cows. For the Benelux countries, Huirne et al. (6) took all the relevant factors into account and calculated that the optimal calving interval for first lactation cows is still exactly one year, while for older cows the interval is even shorter than one year! Lengthening the calving interval from 12 to 13 months causes a loss of $1.50 €$ per day, while the loss due to further lengthening amounts to $2 €$ per extra day. Finally, the average loss per cow culled for disappointing fertility reasons was determined to be $220 €$.

\section{Pathways to subfertility}

On the basis of the surveys mentioned above, the "syndrome of subfertility" can be divided into two major pathways. The first possible way to subfertility is the resumption of normal ovarian activity early postpartum, which is retarded in high producing dairy cows. These cows have a high proportion of abnormal estrous cycles (12). The presence of normal follicular growth on the ovary determines the interval from parturition to first AI. Several studies have determined the major risk factors for ovarian dysfunctions. Much of the research effort has been focused on alterations in endocrine signaling (hypothalamus-pituitary-ovary axis). Correlations were found between energy balance, body condition and blood parameters (such as NEFA, glucose, insulin and insulin-like growth factor I) and the resumption of ovarian activity. Despite this vast amount of excellent research, a lot of work still has to be done. What do we know, for example, about the influence of receptor and post-receptor effects for insulin and gonadotrophines at the level of the follicular cells in the ovary? Is it possible that the metabolic changes characterizing the period of negative energy balance (NEB) have toxic effects on granulosa or theca cells? What subtle signals determine the fate of a preovulatory follicle: atresia, ovulation or a prolonged growth phase resulting in cyst formation?

However, even when a positive energy balance and correct endocrine signaling are re-established, which ultimately results in ovulation, reproduction is still not guaranteed. Early embryonic mortality is proposed to be a significant cause of reproductive failure in ruminants. Thus in addition to the resumption of ovarian activity, oocyte and embryo quality are two further crucial points determining reproductive efficiency. It is only recently that some studies have begun to focus on the oocyte and subsequent embryo quality. And indeed, oocyte quality could be in danger in high producing dairy cows. A field trial performed at our lab revealed that embryos from high yielding dairy cows are inferior compared to the embryos of non-lactating dairy heifers or beef cows (8). Furthermore, we were able to demonstrate that high NEFA and low glucose environments during oocyte maturation are detrimental for the oocyte's developmental competence But what do we know about the specific environment of the oocyte or embryo? It is crucial for further research to investigate the follicular, oviductal and uterine environment thoroughly and to learn more about how this microenvironment can be influenced. Finally, good corpus luteum quality and optimal maternal pregnancy recognition are unmistakably important in establishing a successful gestation.

\section{How to use all this new knowledge in practice?}

The biggest challenge for practitioners is to "translate" the recent knowledge into practice and to use it to help the herds they have in their herd health control program to achieve acceptable levels of fertility. Just as modern herd health control programs should focus on taking preventive measures rather than on increasing the number of curative treatments (3), modern dairy managers should focus on preventive measures in adapting to the current level of milk production. Hence, not only modern cows but also their "coaches" need to adapt to the current high level of milk production. This adaptation has to do with an optimizing of the management! For practicing veterinarians, it should be clear that implementing a dairy herd fertility control program should involve more than just putting their arms in cows' rectums to check for problems. Giving advice on the management of "top dairy athletes" to prevent health and fertility problems most assuredly requires even more energy, knowledge and experience.

\section{Factors influencing fertility and measures to be taken to optimize them}

\section{Infectious diseases affecting reproduction}

The currently encountered herd expansion and intensive housing conditions increase the risk of transmission and maintenance of infectious diseases that are known to compromise reproductive efficiency (Bovine Herpes Viruses [IBR], Bovine Viral Diarrhea Virus [BVDV], salmonellosis, leptospirosis, Neospora caninum). Results from clinical examinations, laboratory results and vaccination regimens need to be drawn together to get a picture of the relevance of the individual infectious agents going around in the 
herd. The targeting and eradication of infectious diseases must be a priority in the maintenance both of herd health and herd fertility. Details of systematic preventive herd health programs against BVDV, IBR, leptospirosis, Johne's disease, salmonellosis and neosporosis should be clearly outlined and thoroughly discussed with the herd manager. Appropriate biosecurity plans should also be implemented to prevent the introduction of new agents into the herd (17).

\section{Negative energy balance}

As negative energy balance (NEB) seems to be the ever-returning enemy of good fertility in high yielding dairy herds, the basic strategy to reduce the reproductive decline should definitely focus on keeping the NEB under control. While in modern dairy cows genetic progress in terms of milk yield has outstripped that for intake capacity, a certain degree of NEB is inevitable, certainly in early lactation (19). The extent of the NEB (both in depth as well as in duration) varies with the magnitude and rate of increase of milk yield compared to energy intake, however, and thus can be exacerbated if metabolic conditions, disease, housing or management practices impair nutrient intake. Hence, management strategies by which the effect of a NEB can be limited must be targeted towards increasing nutrient intakes, especially energy. Immediately after calving, the paramount goal should be to maximize energy intake without disturbing rumen fermentation. The first aim of the management of a recently calved dairy cow is to optimize her general health status. Only when optimal health - including an excellent appetite - is achieved, the focus can shift towards achieving an optimal production level. In practice, in their enthusiasm to reach top production levels, farmers often forget this basic principle.

To optimize energy intake, all the while assuring optimal rumen fermentation, the intake of high quality forages in early lactation should be maximized. Once this has been achieved, the energy density of the ration may be increased by gradually raising the amount of concentrates. Generally, under European circumstances, the maximum amount of concentrates given should not exceed $12 \mathrm{~kg}$ ( $9 \mathrm{~kg}$ in first lactation animals) and should only be reached at three weeks after calving. Increasing the amount of concentrates too fast may disturb ruminal fermentation, which in turn may give rise to ruminal acidosis and an increased incidence of left abomasal displacement.

Currently a lot of research is going on to study the effect of changing the proportion of the different ingredients of the ration. Increasing the amount of fat to maximize the energy content of the ration and hence the energy intake by the animal (10), or increasing the amount of glucogenic substances to temper the steep insulin decrease around the moment of calving (5) are excellent illustrations of such measures. For example, the ratio of $n 6: n 3$ fatty acids provided in the diet can influence the synthesis of the 2 -series of prostaglandins, which are desirable after calving to speed up uterine involution, but undesirable after insemination as they can contribute to the breakdown of the corpus luteum of pregnancy. Hence, the practical implementation of our current knowledge needs to be a better timing of the introduction of rumen protected fats into the diet in accordance with the reproductive stage of the cow. Although primary results seem to be promising, these studies need further confirmation before definite conclusions can be drawn and the results transferred into practical recommendations.

Nutrient or dry matter intake is highly dependent on a lot of factors related both to the cow and to the environment. Among the cow factors, the general health status and body condition score are of major importance. Hence, transition cow programs should focus on maximizing general health and appetite and striving for the ideal body condition score of 3.5 (on 5-point scale) at calving. Aiming for optimal general health includes trimming of the claws at drying off, optimizing rumen health and avoiding metabolic and infectious diseases around calving. Besides this, the veterinarian should provide his herds with a specifically designed standard operating procedure for detecting ill cows as soon as possible and treating them properly.

Furthermore, efforts must be made to remove any environmental restrictions to feed intake, as the environment must be conducive to high intake. Cows need time and space for undisturbed feeding and rumination. There is clear evidence now that the design of food passages, barriers, troughs for water supply and cow traffic within the building definitely affect the intake cows will achieve (1). Intake can vary widely between individuals in a herd with a lot of competition for feeding space. Especially the intake of heifers is easily restricted by competition with older cows. The provision of adequate feeding space reduces this kind of competition largely. The grouping of cows and social behavior also have their implications. A lot of attention should be paid to this point because during the transition period cows are transferred several times from one group to another. Each transfer or relocation implies another challenge for the cows as it brings them in contact with a new group and a new ration. All the energy that is spent in establishing a new social hierarchy is no longer available to produce or reproduce. At the same time, each change in the ration causes a serious drop in dry matter intake and should therefore also be avoided (1).

Although veterinary practitioners are currently not the only advisors on modern dairy herds, they have the advantage that they can use their "clinical eyes" to interpret what is happening in the herd. Besides the use of herd production data which are usually readily available, the use of clinical scoring systems has been proven to provide the veterinarian with an extra tool to evaluate the health status of the animals in relation to their production level. Hence, these scoring systems should be used to evaluate the management system used on the herds at a regular time interval.

Furthermore, today's dairy cows may face a wide variety of environmental stressors. These may include overcrowding, infectious challenges, poor ventilation, poor footing or other forms of chronic or even acute pain, uncomfortable stables, rough handling, and frequent relocation in another group. Most of these stressors affect fertility and should therefore be avoided (4). Although stress is difficult to define and to show to the herd manager, a lack in cow comfort compromising the cows' health and fertility 
should be noticed and discussed during the regular herd health visits. While top managers have it at their finger-tips and do not need a lot of explanation to adapt their herd to the needs of their modern top producers, others definitely need to be confronted with some eye-openers.

\section{Heat detection}

As has been noted for a long time already, under European conditions where it is not feasible to commonly use synchronization protocols, one of the most important limitations of the reproductive performance of a cattle herd is poor detection of estrus $(2,14)$. Besides the higher incidence of ovarian disturbances in high yielding dairy cows, the expression of heat symptoms is also reported to be diminished. For example, less than $50 \%$ of the estrous cows "stand to be mounted" (9). Therefore some authors propose using other - or more than one - behavioral signs besides this long recognized gold standard to declare a cow in heat $(7,21)$. The fact that the "stand to be mounted" reflex is being significantly less displayed, implies that the aids for detecting estrus which are based on it are currently losing their applicability to a large extent. The use of other aids such as activity meters, however, seems to be giving promising results. Systems for automatically collecting diagnostic data may also provide a gentle solution in this respect. For example, an in-line sensor to measure progesterone and hence to detect the presence or absence of a corpus luteum may be a futuristic though powerful tool to enhance reproductive performance in some herds (15).

While a lot of recent research is obviously directed towards the investigation of the influence of the energy balance and the stressed metabolism on the expression of heat symptoms, one may not forget to take into consideration all management changes which took place while moving towards high yielding herds. Several studies have clearly shown that primary behavioral signs such as mounting and standing may be seriously depressed by the immediate environmental conditions. For example, it is well known that the expression of heat has seriously decreased since the overall use of concrete floors. Cows furthermore dislike being mounted by herdmates if the floor surface is either slippery or very coarse (20). Cows with leg or foot problems, regardless of whether the problem is structural, clinical or subclinical, show much less mounting activity. Many of the foot problems affecting mounting activity can be alleviated by proper foot care and trimming. Other recommendations which should be given to farmers in order to prevent the problem of anestrus include spending more time on estrus detection, looking at both primary and secondary signs of estrus and increasing the amount of light in the stall (21).

\section{Moment of insemination, insemination technique and sperm quality}

The aforementioned decrease in heat symptoms often forces farmers to inseminate their cows based on secondary heat symp- toms. The "use" of these symptoms, however, significantly increases the risk of inseminations not being performed at the optimal moment in relation to the moment of ovulation. This may be seen as a significant contributor to the universally recognized decline in pregnancy results in modern dairy herds. As has been known for the past 60 years, insemination should take place from 24 to 12 hours before ovulation in order to attain the highest pregnancy rate. Roelofs (16) also found that insemination during this time interval provided the best chance of ending up with a good quality embryo at day 7 after insemination. The correct use of this rule, however, depends largely on how many times and for how long heat detection is performed during the day, and which heat symptoms are taken into account. If pedometers are used, the correct timing of insemination according to the increase in activity seems to be the best strategy because this increase in activity is observed in most of the estrus periods, and these activity meters are relatively easy to implement in dairy practice.

In addition, the insemination technique and sperm quality are important factors contributing to acceptable fertility. The majority of the dairy herds use artificial insemination (AI) and currently many owners are performing "do it yourself AI". Proper training and monitoring of the procedures are paramount in getting good results. Sire selection, on the other hand, is usually focused on production and physical traits but should also take into account reproductive efficiency. Only those sires should be used that have above average non-return rates. If natural breeding is used, pregnancy rates are consistently 10-20\% higher than with AI. For this reason, farmers often use a bull for their problem cows that have been inseminated three or four times without getting pregnant.

\section{Housing}

Many diseases are associated with the housing of the cows, as is subfertility. For example, slippery floors are very detrimental to estrus expression. The goal in housing design is to provide an environment for the cows that has a positive effect on their health and fertility. Good housing is furthermore essential during calving (11). Parturient cows should be placed in separate, clean maternity facilities to guarantee sanitary conditions. Strict hygienic measures should be used during parturition in order to prevent infections of the genital tract (3). If the cow's housing environment is insufficient, further measures should be taken to meet the animals' requirements. The bedding of the cubicles, the flooring and the possibilities for guaranteeing optimal hygiene are among the most important factors in this respect.

\section{Conclusion}

In view of the complex nature of fertility, it is not surprising to find that ideal fertility criteria are extremely difficult to achieve. When infections are involved in a subfertility problem, this can be due either to specific (e. g. BVDV) or non-specific genital infections. The former often strike a whole herd, causing abortions and 
repeat breeding. The latter are opportunists of unsanitary conditions during calving, dystocia and abnormal puerperium. They often take an insidious course.

It is generally agreed, however, that the main negative influence on the fertility of a dairy herd stems not as much from specific or non-specific infections, but rather from the effects of a host of other factors. These factors seldom exert their effects individually but rather interact together, making it difficult to analyze infertility in a given herd. For example, the advancement of animal husbandry practices has increased both herd size and production, but man hours per cow have dwindled. The direct result of this decrease is that less time remains for detecting heats, instituting hygienic measures and trimming claws. Thus the final fertility status of a dairy herd is the result of interactions of a whole range of factors from environmental conditions such as season, herd size and age composition, to pure managerial factors such as breeding policy, nutrition and estrus detection. Breeding efficiency depends almost totally on whether or not the farmer is able to skillfully cope with these factors in his herd. By way of conclusion, subfertility has been proven to be a multifactorial disease and the optimization of herd fertility often requires the optimization of several interfering managerial factors. There is almost never a single solution. Although poor fertility is becoming more and more common in our top dairy herds, there is a wide variation between herds and sometimes between years within the same herd. This latter fact illustrates that the dairy herd acts as a dynamic structure and may need specific adaptations, depending on the specific situations the herd actually has to face.

Fertility of a dairy herd is thus a relative phenomenon, expressing what the cows have been able to achieve in the face of a host of interacting factors. To avoid a deterioration of fertility below the accepted standards, the advice given to the farmer should enable him to optimally manage his herd under the given environmental and management conditions. Such advice can best be given by paying regular visits to the farmer (Herd Health and Fertility Control Program) so as to impress upon him the relevant factors of management. Hence, the follow-up of the reproductive performance of a dairy herd should be continuous and not only be restricted to the curative interventions when things are really going wrong.

The cornerstone to improving the reproductive performance of lactating dairy cattle also involves the understanding of the biochemical and physiological principles controlling reproductive and lactational processes. The challenge is to integrate this knowledge into nutritional management, production medicine and reproductive management procedures, taking into account the specific obstacles each individual herd has to face, for the purpose of optimizing the fertility of the herd (18). In the absence of such a holistic approach, the response to traditional veterinary therapies and herd health programs may increasingly diminish.

\section{Literatur}

1. Cook N, Nordlund K. Behavioral needs of the transition cow and considerations for special needs facility design. Vet Clin North Am Food Anim Pract 2004; 20: 495-520

2. De Kruif A. Factors influencing the fertility of a cattle population. J Reprod Fert 1978; 54: 507-518.

3. De Kruif A, Opsomer G. Integrated dairy herd health management as the basis for prevention. In: "Recent developments and perspectives in bovine medicine"; Keynote lectures of the XXII World Buiatrics Congress, 18-23 August 2002, Hannover, Germany; 410-419.

4. Dobson H, Smith RF. What is stress, and how does it affect reproduction? Anim Reprod Sci 2001; 60-61: 743-752.

5. Gong JG, Lee WJ, Garnsworthy PC, Webb R. Effect of dietary-induced increases in circulating insulin concentrations during the early postpartum period on reproductive function in dairy cows. Reproduction 2002; 123: 419-427.

6. Huirne R, Saatkamp H, Bergevoet R. Economic analysis of common health problems in dairy cattle. In: 'Recent Developments and Perspectives in Bovine Medicine.' Keynote Lectures of the XXII World Buiatrics Congress, 18-23 August, 2002, Hannover, Germany; 420-431.

7. Kerbrat S, Disenhaus C. A proposition for an updated behavourial characterisation of the oestrus period in dairy cows. Appl Anim Behav Sci 2004; 87: 223-238.

8. Leroy J. Metabolic changes in high producing dairy cows and the consequences on oocyte and embryo quality. PhD Thesis, Faculty of Veterinary Medicine, Ghent University 2005; 252

9. Lopez H, Satter L, Wiltbank M. Relationship between the level of milk production and estrous behavior of lactating dairy cows. Anim Reprod Sci 2004; 81: 209-223.

10. Mattos R, Staples CR, Thatcher WW. Effects of dietary fatty acids on reproduction in ruminants. Rev Reprod 2000; 5: 38-45.

11. Mee J. Managing the dairy cow at calving time. Vet Clin North Am Food Anim Pract 2004; 20: 521-546.

12. Opsomer G, Coryn M, Deluyker H, de Kruif A An analysis of ovarian dysfunction in high yielding dairy cows after calving based on progesterone profiles. Reprod Dom Anim 1998; 33: 193-204.

13. Opsomer G, Gröhn Y, Hertl J, Coryn M, Deluyker H, de Kruif A. Risk factors for postpartum ovarian dysfunction in high producing dairy cows in Belgium: a field study. Theriogenology 2000; 53: 841-857.

14. Opsomer G, Leroy J, Vanholder T, Bossaert P, de Kruif A. Subfertility in high yielding dairy cows: how to bring science into practice? Vlaams Diergeneeskundig Tijdschrift 2006; 75: 113-119.

15. Pemberton R, Hart J, Mottram T. An electrochemical immunosensor for milk progesterone using a continuous flow system. Biosensors and Bioelectronics 2001; 16: 715-723.

16. Roelofs JB, Soede NM, Kemp B. Insemination strategy based on ovulation prediction in dairy cattle. Vlaams Diergeneeskundig Tijdschrift 2006; 75: 70-78.

17. Sanderson M, Gnad D. Biosecurity for reproductive diseases. Vet Clin North Am: Food Anim Pract 2002; 18: 79-98.

18. Thatcher W, Bilby T, Bartolome J, Silvestre F, Staples C, Santos J. Strategies for improving fertility in the modern dairy cow. Theriogenology 2006; 65: $30-44$.

19. Thomas C, Leach KA, Logue DN, Ferries C, Phipps RH. Management options to reduce load. In: Metabolic stress in dairy cows. Occasional publication No. 24 - British Society of Animal Science. Oldham JD, Simm G, Groen AF, Nielsen BL, Pryce JE. Lawrence TLJ, eds.; 1999; 129-139.

20. Vailes L, Britt J. Influence of footing surface on mounting and other sexual behaviors of estrual Holstein cows. J Anim Sci 1990; 68: 2333-2339.

21. Van Viet J, Van Eerdenburg F. Sexual activities and oestrus detection in lactating Holstein cows. Applied Animal Behaviour Science 1996; 50: 57-69.

Aart de Kruif

Department of Reproduction,

Obstetrics and Herd Health

Faculty of Veterinary Medicine

Salisburylaan 133, 9820 Merelbeke, Belgium

E-Mail: Aart.deKruif@UGent.be 